\title{
Clinicohematological Evaluation of Leukemias in a Tertiary Care Hospital
}

\author{
${ }^{1}$ Dr. Akanksha Bothale Salkar, ${ }^{2}$ Dr. Anjali Patrikar, ${ }^{3}$ Dr. Kalpana Bothale \\ ${ }^{4}$ Dr. Sadhana Mahore, ${ }^{5}$ Dr. Amit Salkar, ${ }^{6}$ Dr.Shruti Modani \\ ${ }^{1}$ (Resident), ${ }^{2}$ (Associate Professor), ${ }^{3}$ (Associate Professor), ${ }^{4}$ (Prof And Head), ${ }^{5}$ (Lecturer), ${ }^{6}$ (Resident) \\ ${ }^{12346}$ Department Of Pathology, Department of Medicine, Nkp Salve Institute Of Medical Sciences, Nagpur.
}

\section{Introduction}

Leukemias are neoplastic proliferations of haematopoietic cells and form a major proportion of haematopoietic neoplasms that are diagnosed worldwide. Leukemias are classified into two broad groups, myeloid and lymphoid, based on the origin of the leukemic stem cell clone.

Diagnosing the type and sub-type of leukemia is very important as the therapy, prognosis and survival rate changes with each type and sub-type.

Although the French American British (FAB) morphologic classification of myeloid and lymphoid neoplasms has been used since many years, the discovery of number of genetic lesions that predict the clinical behavior and outcome better than morphology alone, necessitates the incorporation of specific genetic data in the classification scheme. ${ }^{1}$

The diagnosis of acute leukemia entails a stepwise approach. First in the sequence and importance is the distinction of acute leukemia from other neoplastic diseases and reactive disorders. Second is differentiating acute myeloid (AML) and acute lymphoblastic (ALL) leukemia. The third facet is the classification of AML and ALL into categories that define treatment and prognostic groups. In most cases, the first two facets of the diagnosis of acute leukemia can be achieved by careful morphological assessment of blood and bone marrow smears and marrow trephine biopsy sections. ${ }^{2}$ By assessing the morphologic features together, a majority of cases of AML and ALL can be accurately diagnosed . In some cases of poorly differentiated acute leukemia, however, the morphologic features may be equivocal, requiring additional studies.

The present study was conducted to diagnose and classify the types and sub-types of leukemias by a combination of morphology on peripheral smear and bone marrow aspirates. Clinical features and hematological findings in leukemias are also studied. Cytochemistry was used in acute leukemia cases for subtyping as per FAB classification and immunophenotyping was done wherever possible in occasional cases.

\section{Aims And Objectives}

1. To classify leukemias and subtype acute leukemias with the help of cytochemistry according to French American British (FAB) Classification.

2. To study the clinical manifestations of various types of leukemias.

3. To analyse the demographic data (age and sex distribution) in various types of leukemias.

\section{Material And Methods}

This Clinico-hematological laboratory based study spanned over a period of 2 years. Peripheral venous blood and bone marrow aspirate samples of clinically suspected leukemia patients received at the Department of Pathology, NKPSIMS, were studied.

INCLUSION CRITERIA - Peripheral blood smear and bone marrow aspirates (wherever essential) from patients of all age groups who presented with clinical features and abnormal hematological findings suggestive of leukemia.

EXCLUSION CRITERIA - Other hematological malignancies like lymphomas and multiple myelomas were excluded.

The relevant clinical history was obtained in each case, routine blood counts performed and peripheral smear and bone marrow aspirates studied in detail. Smears were stained with standard Romanowsky stains( Leishman stain) and studied for morphology of cells. Hematological investigations were done on a 3 part cell counter. Cytochemical stains such as Myeloperoxidase, Non specific esterase, Sudan Black B and Periodic acid schiff were done wherever needed for typing acute leukemia cases. Kits manufactured by FAR SRL from Verona Italy were used for cytochemistry. 
III. Results

Table 1: Distribution of patients according to age

\begin{tabular}{|l|l|l|}
\hline Characteristic & No. & $\%$ \\
\hline Age in years & & \\
\hline$\leq 10$ & 11 & 10 \\
\hline $11-20$ & 19 & 17.27 \\
\hline $21-30$ & 6 & 5.45 \\
\hline $31-40$ & 21 & 19.09 \\
\hline $41-50$ & 23 & 20.91 \\
\hline $51-60$ & 16 & 14.55 \\
\hline$\geq 61$ & 14 & 12.73 \\
\hline Total & 110 & 100 \\
\hline
\end{tabular}

Table 1 provides the distribution of patients according to age. It is evident that majority, i.e. 23 (20.91\%) patients were in the age range of 41-50 years, followed by $21(19.09 \%)$ cases in the age group of 3140 years and $19(17.27 \%)$ cases in the range of $11-20$ years.

Table 2- Distribution of patients according to gender

\begin{tabular}{|l|l|l|l|}
\hline Gender & No. & $\%$ & Gender \\
\hline Male & 71 & 65 & Male \\
\hline Female & 39 & 35 & Female \\
\hline Total & 110 & 100 & Total \\
\hline
\end{tabular}

Table 2 gives the distribution of patients as per gender. The sample had male dominance with $71(65 \%)$ cases, while there were $39(35 \%)$ females in the study.

Table 3 : Distribution of patients according to type and sub-types of leukemia

\begin{tabular}{|l|l|}
\hline Type and sub-types of leukemia & No. $(\%)$ \\
\hline AML $(\mathrm{n}=43)$ & \\
\hline M1 & $6(13.95)$ \\
\hline M2 & $19(44.19)$ \\
\hline M3 & $15(34.89)$ \\
\hline M4 & $2(4.65)$ \\
\hline ALL $(n=28)$ & $1(2.32)$ \\
\hline L1 & \\
\hline L2 & $13(46.42)$ \\
\hline CML $(n=30)$ & $15(53.58)$ \\
\hline CP & \\
\hline AP & $22(73.33)$ \\
\hline BC & $5(16.67)$ \\
\hline CLL $(n=9)$ & $3(10.00)$ \\
\hline CLL & \\
\hline PLL & $8(88.89)$ \\
\hline
\end{tabular}

Table 3. provides the distribution of patients according to types and sub-types of leukemia. In the AML group, $19(44.19 \%)$ and $15(34.89 \%)$ cases belonged to M2 and M3 sub-types respectively. In the ALL group, the number of L1 and L2 sub-types were $13(46.42 \%)$ and $15(53.58 \%)$ respectively. In the CML group, out of 30, $22(73.33 \%)$ were in Chronic phase.

Table 4: Comparison of hematological parameters with reference to clinical features

\begin{tabular}{|l|l|l|l|}
\hline Signs & $\mathrm{Hb}(\mathrm{gm} / \mathrm{dl})$ & $\mathrm{TLC}(/ \mu \mathrm{l})$ & Platelet count $(\mathrm{lacs} / \mathrm{cmm})$ \\
\hline Pallor $(\mathrm{n}=104)$ & $7.22 \pm 2.17$ & $110600 \pm 97574.8$ & $157586.5 \pm 217181.4$ \\
\hline Lymphadenopathy $(\mathrm{n}=51)$ & $7.16 \pm 2.14$ & $83250 \pm 87793.3$ & $141019.6 \pm 189731.8$ \\
\hline Hepatomegaly $(\mathrm{n}=94)$ & $7.20 \pm 2.20$ & $94306 \pm 73551.4$ & $159968.1 \pm 212943$ \\
\hline Spleenomegaly $(\mathrm{n}=90)$ & $7.09 \pm 2.25$ & $96426 \pm 72400.1$ & $165411.1 \pm 216029.3$ \\
\hline P-value* & 0.974 & 0.728 & 0.93 \\
\hline
\end{tabular}

*Obtained using one-way ANOVA

In case of hemoglobin, patients with pallor had highest mean level of $7.22 \pm 2.17 \mathrm{gm} / \mathrm{dL}$; while the least was obtained for splenomegaly with $7.09 \pm 2.25 \mathrm{gm} / \mathrm{dL}$. The difference in the mean Hb levels was statistically insignificant across clinical features as revealed by a $\mathrm{P}$-value of $0.974(\mathrm{P}>0.05)$.

In case of TLC, the highest count was observed for patients with pallor $(110600 \pm 97574.8 / \mu 1)$; while least was observed for lymphadenopathy $(83250 \pm 87793.38 / \mu 1)$. The difference in the mean count across groups was statistically insignificant with $\mathrm{P}$-value of $0.728(\mathrm{P}>0.05)$. 
For platelet count, the maximum mean was obtained for splenomegaly $(165411.1 \pm 216029.3$ lacs $/ \mathrm{cmm})$; while the minimum was obtained for lymphadenopathy $(141019.6 \pm 189731.8 \mathrm{lacs} / \mathrm{cmm})$. The difference in the mean levels across features was statistically insignificant with P-value of 0.93 ( $\mathrm{P}>0.05)$.

Table no. 5- Different hematological parameters according to type of leukemia $(n=110)$

\begin{tabular}{|c|c|c|c|c|}
\hline Parameters & $\operatorname{AML}(n=43)$ & $\operatorname{ALL}(n=28)$ & CML $(n=30)$ & $\operatorname{CLL}(\mathrm{n}=9)$ \\
\hline Age range in years & $8-70$ & $3-38$ & $20-70$ & $56-80$ \\
\hline Mean \pm SD: $\mathrm{Hb}(\mathrm{gm} / \mathrm{dL})$ & $6.80 \pm 2.29$ & $6.89 \pm 1.93$ & $8.47 \pm 2.11$ & $7.31 \pm 2.79$ \\
\hline Mean \pm SD: TLC $($ per $\mu \mathrm{l})$ & $79365.1 \pm 75126.4$ & $\begin{array}{l}62060.7 \\
55786.6\end{array}$ & $\begin{array}{ll}138110 & \pm \\
66115 . .2 & \end{array}$ & $\begin{array}{l}61466.7 \\
59016 . .2\end{array}$ \\
\hline Mean \pm SD: Platelet count $(\mathrm{lacs} / \mathrm{cmm})$ & $65930.2 \pm 68856.4$ & $\begin{array}{l}58785.7 \\
25623.1 \\
\end{array}$ & $\begin{array}{ll}400100 & \pm \\
285334.7 & \\
\end{array}$ & $\begin{array}{l}156222.2 \\
\pm 153621.1 \\
\end{array}$ \\
\hline Median Blast cell (\%) & 70 & 56.5 & 3 & 0 \\
\hline
\end{tabular}

Table 5 provides the descriptive statistics for hematological parameters according to leukemia types. The maximum mean hemoglobin level $(8.47 \pm 2.11 \mathrm{gm} / \mathrm{dL})$ was observed in CML patients, while the minimum mean was observed for AML group $(6.80 \pm 2.29 \mathrm{gm} / \mathrm{dL})$.

Further, the mean TLC count in CML group was maximum i.e. $138110 \pm 66115.2 / \mu 1$, while the least was observed for CLL patients $(61466.7 \pm 59016.2 / \mu \mathrm{l})$. The significance analysis resulted into a P-value < 0.0001 indicating highly significant difference across leukemia types.

The mean platelet count in CML group was maximum $(400100 \pm 285334.7 \mathrm{lacs} / \mathrm{cmm})$, while that in ALL group was minimum $(58785.7 \pm 25623.1 \mathrm{lacs} / \mathrm{cmm})$. The difference in the mean levels was statistically significant with $\mathrm{P}<0.0001$.

The median blast cell was highest in AML group with 70\%, followed by ALL group with 56.5\%. In CML group, it was only $3 \%$, while no cases showed blast cell in CLL group.

Table no. 6- Distribution of acute cases as per cytochemistry $(n=71)$

\begin{tabular}{|l|l|l|}
\hline Cytochemistry & AML & ALL \\
\hline MPO+, SBB+, PAS- & $38(88.37)$ & 0 \\
\hline MPO+, SBB+, PAS+ & $3(6.98)$ & 0 \\
\hline MPO+, NSE+, PAS- & $2(4.65)$ & 0 \\
\hline MPO-, SBB-, PAS+, & 0 & $21(75.00)$ \\
\hline MPO-, SBB+, PAS+ & 0 & $5(17.86)$ \\
\hline MPO-, SBB-, PAS- & 0 & $2(7.14)$ \\
\hline Total & $43(39.09)$ & $28(25.45)$ \\
\hline
\end{tabular}

\section{Discussion}

Hematological malignancies are quite common and affect all ages and genders. The diagnosis involves a multiparameter approach including morphologic examination and phenotypic or genotypic studies. ${ }^{3}$

In the present study, 110 cases of leukemia were evaluated by studying the detailed clinical features, morphology on peripheral blood smear and bone marrow aspiration (wherever essential) and cytochemistry to arrive at a final diagnosis. The duration of the study was of 2 years.

Out of the 110 cases we found that 71 cases were of acute leukemia and 39 cases of chronic leukemia. Out of which 43 were of acute myeloid leukemia, 28 of acute lymphoid leukemia. There were 30 cases of CML and 9 cases of CLL.

Acute leukemia was more common than chronic leukemia. Similar findings have been reported by Idris $\mathrm{M}$ et $\mathrm{al}^{4}, \mathrm{Al}$ Ghazaly et $\mathrm{al}^{5}$ and Rathee $\mathrm{R}$ et $\mathrm{al}^{6}$ in their studies.Among lymphoid leukemias in our series, ALL was far more common 28/110 than CLL 9/110. We found a male preponderance in our study with M: F ratio of 1.85:1. In our study, out of 43 cases of AML, $36(84 \%)$ were adults and $7(16 \%)$ were children and out of 28 cases of ALL, $17(61 \%)$ were children and $11(39 \%)$ were adults.So, AML was more common in adults and ALL in children.

All the CML and CLL cases were adults mainly in 41-50 years age group and >61 years age groups respectively.

After subtyping acute leukemia cases with cytochemistryt, we got AML-M2 as the commonest type with 19 cases (17.2\%), followed by M3 with 15 cases (13.64\%), M1- 6 cases (5.45\%), M4- 2 cases (1.82\%). We got only one case of AML-M6 and no cases of AML-M0 and M7. Kulshreshtha et $\mathrm{al}^{7}$ in their study also got AML-M2 as the commonest subtype. 
$>$ All the 43 AML cases were positive for Myeloperoxidase stain/MPO.

$>38$ cases stained positive for Sudan black/SBB along with MPO.

> 2 cases of AML-M4 stained positive for non-specific esterase/NSE stain and MPO.

$>3$ cases of AML came positive for Periodic Acid Schiff stain/PAS along with MPO and SBB of which 2 were diagnosed AML-M3 \& 1 was diagnosed as AML-M6 (Morphologically).

28 cases of ALL were subjected to cytochemistry out of which all cases were negative for MPO.

$>21$ cases were PAS positive.

$>2$ cases were MPO, PAS and SBB negative but on the basis of morphology of blasts they were categorized as ALL-L2.These cases were subjected to flowcytometry and they were T-ALL and B-ALL.

Different types of leukemias have different clinical presentations. In our present study weakness followed by fever and weight loss were the most common symptoms. Bleeding, ecchymosis were seen mainly in acute leukemia cases specially more common in AML-M3. Bone pain was also seen more commonly in AML cases. Pallor was the most common sign followed by hepatomegaly. Lymphadenopathy was more common in ALL. Hepatomegaly was found in acute as well as chronic cases but splenomegaly was the commonest complaint of CML patients.

\section{Conclusion-}

We conclude that myeloid neoplasms were more common than lymphoid neoplasms in our study. The incidence of various types of leukemia varies considerably in different age groups; and there may be population bias which occurs in a tertiary care centre like our institute, leading to variation in the prevalence of different types of leukemias. AML was the commonest type of leukemia in adults and ALL in children.CML and CLL were diagnosed accurately by morphology on peripheral smear and bone marrow. With the help of Cytochemistry and morphology, accurate diagnosis of acute leukemia could be given according to FAB classification in 69 out of 71 cases. Accurate and early diagnosis in these cases help in instituting proper therapy to prevent the possible complications. But in 2 cases where the morphology was ambiguous and cytochemistry was inconclusive, flowcytometry was mandatory to confirm the diagnosis.

Hence, even though morphology and cytochemistry are the gold standards and play a vital role in the accurate diagnosis of leukemias, but the use of the recent techniques like flowcytometry and cytogenetics is essential in difficult cases. But they are costly so it is practically difficult to use these tests for the masses.

\section{Bibliography}

[1]. Harris NL, Jaffe ES, Vardiman JW, Stein H, Diabold J, Flandrin G. WHO Classification of tumors of haematopoietic and lymphoid tissues- Introduction. In: Harris NL, Jaffe ES,Vardiman JW, editors. Pathology and Genetics of Tumors of haematopoietic and lymphoid tissues.Lyon France:IARC press; 2008: 15.

[2]. McKenna RW. Multifaceted Approach to the Diagnosis and Classification of Acute Leukemias. Clinical Chemistry. 2000;46(8 II): $1252-1259$

[3]. Cousar J, Arber DA. Hematopoeitic Tumors: Principles of pathologic diagnosis. In: Greer JP, Rodgers GM, Foerster J, Paraskevas F, Lukens JN, Glader B, editors. Wintrobe's Clinical Hematology.12 ${ }^{\text {th }}$ edition, vol 2. Lipincotts Williams and Wilkins; 2009:164365 .

[4]. Idris M, Shah SH, Fareed J, Gul N. An experience with sixty cases of haematological malignancies; a clinico haematological correlation. J Ayub Med Coll Abbottabad 2004 Oct-Dec;16(4):51-4.

[5]. Al Ghazaly J, Al Selwi AH, Abdullah M, Al Jahafi AK, Al Dubai W, Al Hashdi A. Pattern of Hematological diseases diagnosed by bone marrow examination in Yemen : a developing country experience. Clin Lab Haematol 2006; 28(6):376-381.

[6]. Rathee R, Vashisht M, Kumar A, Singh S. Incidence of acute and chronic forms of leukemia in Haryana, India. IJPPS 2014 March;6:324-325.

[7]. Kulshrestha R, Sah SP. Pattern of occurrence of leukemia at a teaching hospital in eastern region of Nepal - a six year study. JNMA J Nepal Med Assoc. 2009 Jan-Mar;48(173):35-40. 


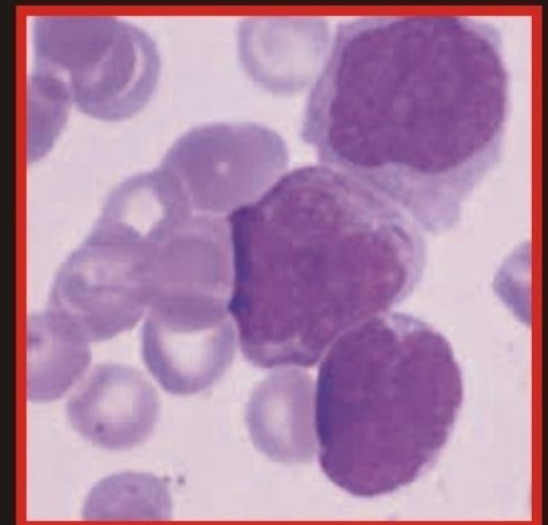

Fig. 1: AML-M1, PS showing Myeloblasts

(Leishman's stain, X1000)

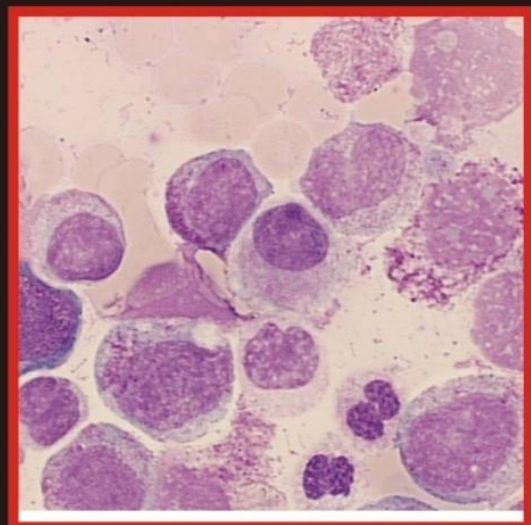

Fig. 2: AML-M2, PS showing Myeloblasts with neutrophils (Leishman's stain, $\mathbf{X 1 0 0 0 )}$

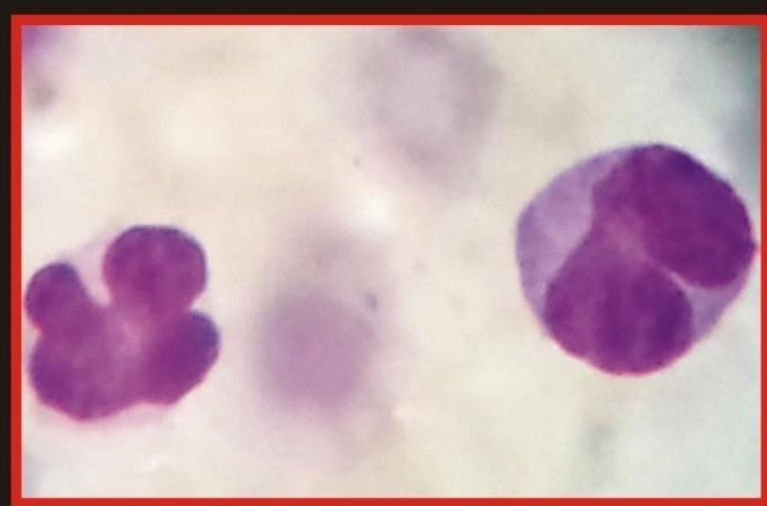

Fig. 3: AML-M3 (Hypogranular variant), PS showing promyelocytes with bilobed nuclei and prominent nucleoli \& hypogranular cytoplasm (Leishman's stain, X1000)

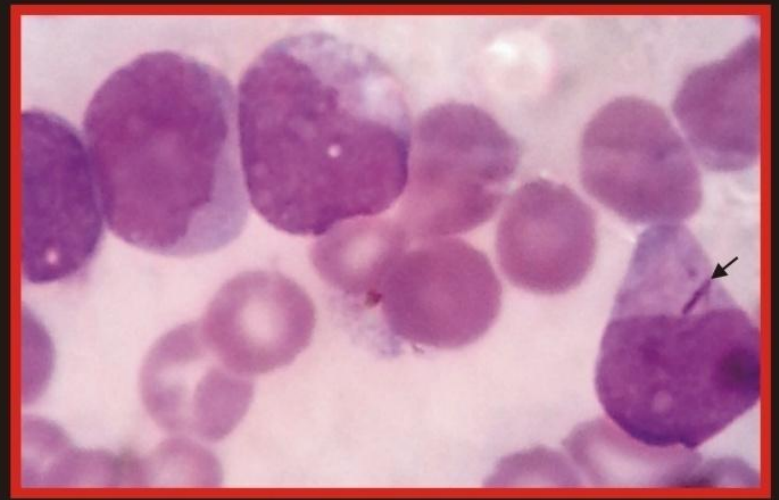

Fig. 4: AML-M4, PS showing blasts of myeloid and monocytic lineage. Myeloblast showing Auer rod. (Leishman's stain, X1000) 


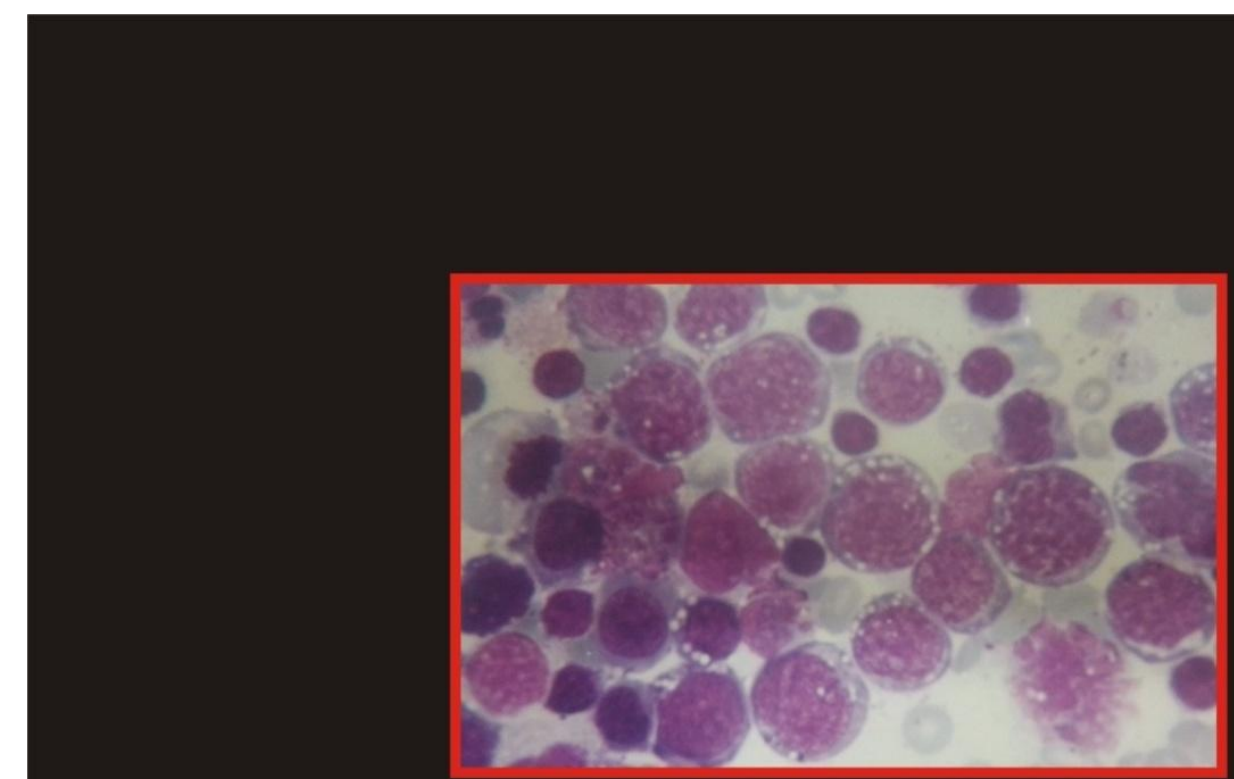

Fig. 5A: Photomicrograph showing involvement of bone marrow by blasts of AML-M6

(Leishman's stain, $X$ 1000)
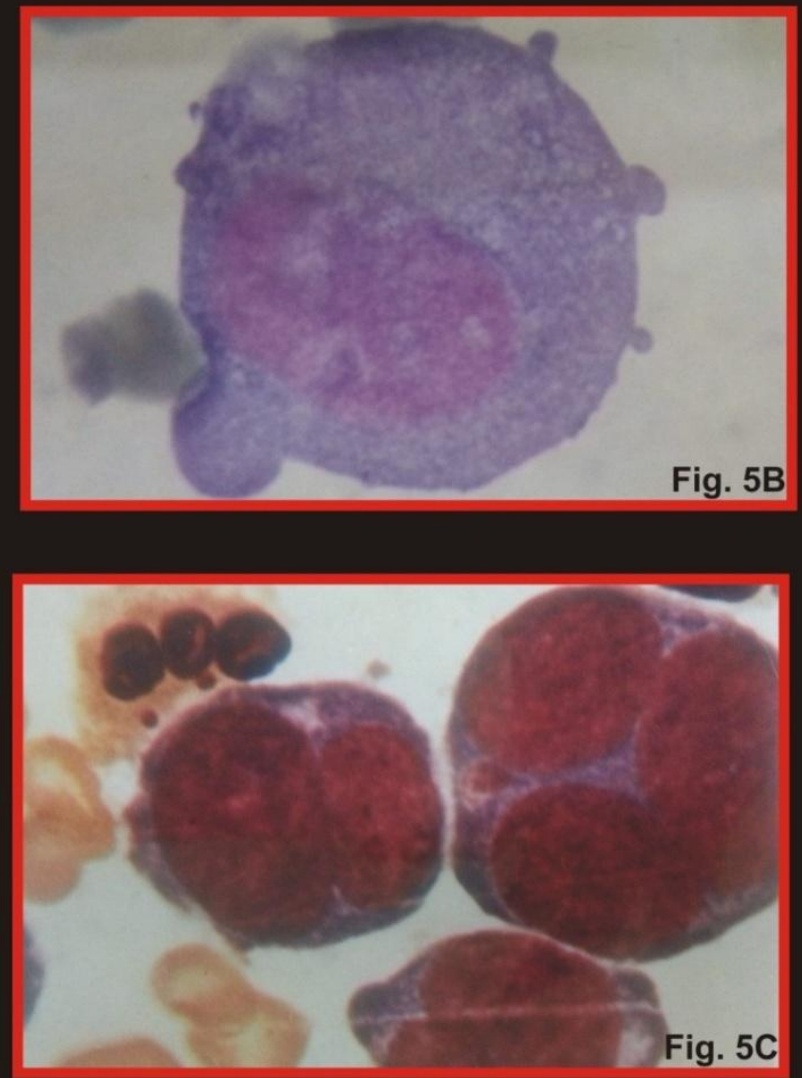

Fig. 5B \& 5C: Photomicrograph depicting large giant cell showing budding \& large Erythroblasts (Leishman's stain $X$ 1000) 


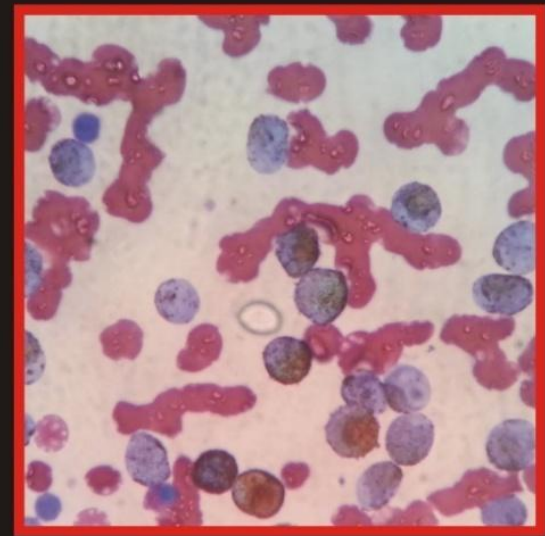

(MPO stain X 400)

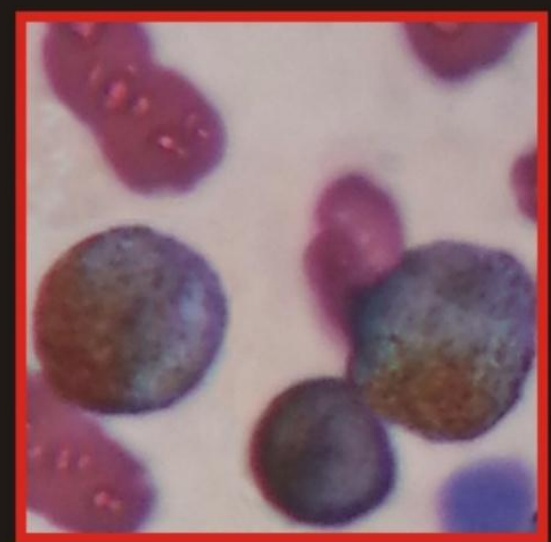

(MPO stain X 1000)

Fig. 6A\&6B: Blasts with positive reaction to Myeloperoxidase Stain

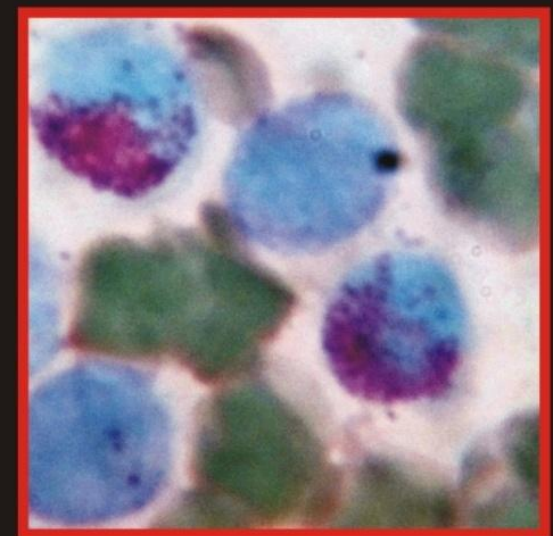

Fig.7A: AML-M4, PS-Monocytic blastsshowing positive reaction to NSE stain (NSE stain X 1000).

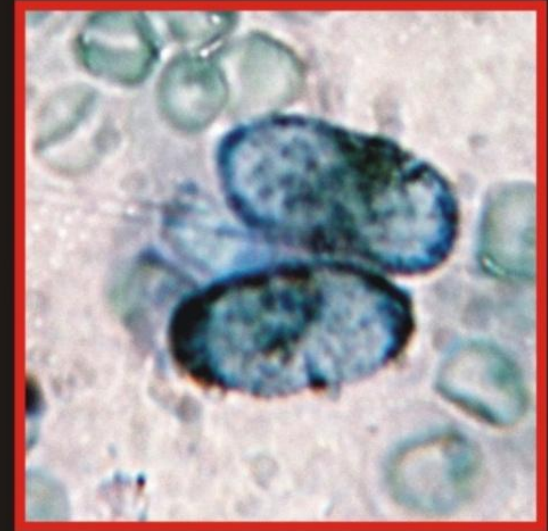

Fig. 7B: BM smear - Myeloblasts with Sudan Black positivity (SBB stain X 1000)

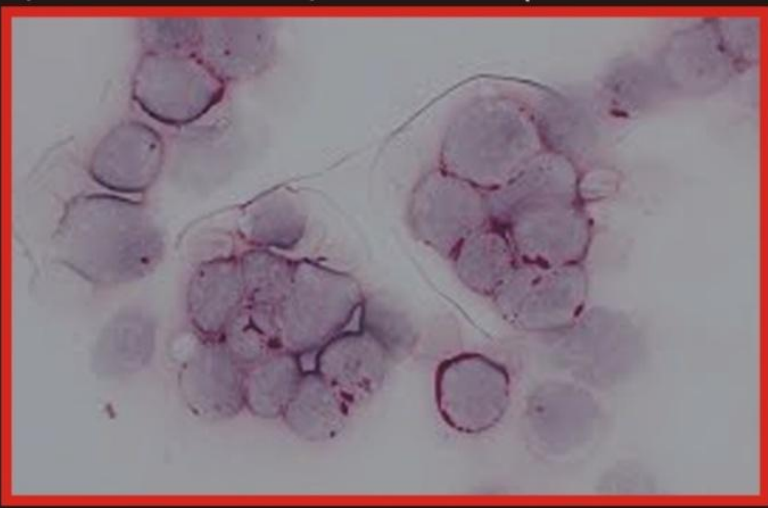

Fig. 8A: ALL- lymphoblasts showing block like positivity on PAS stain (PAS stain X1000). 


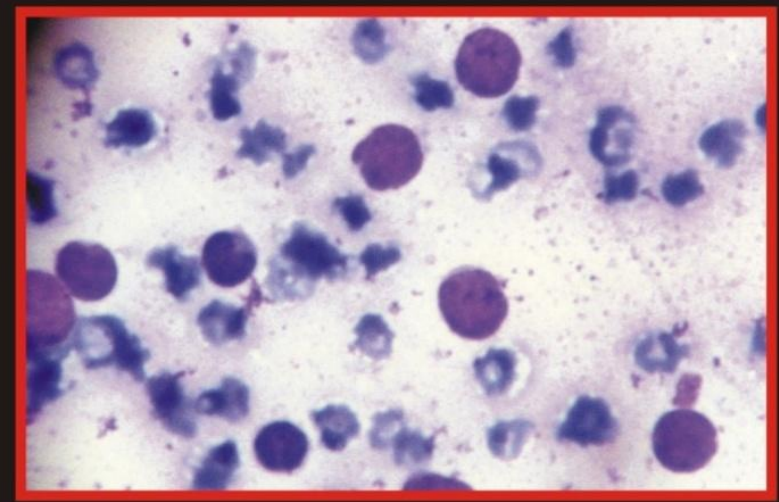

Fig. 8B : ALL-L1, PS showing homogenous blast Population (Leishman's stain, X1000).

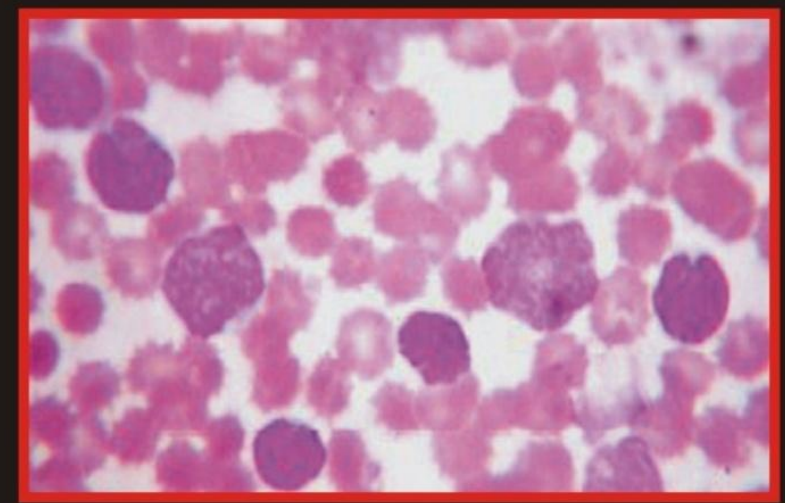

Fig. 8C : ALL-L2, PS showing heterogenous blast population (Leishman's stain, X1000)

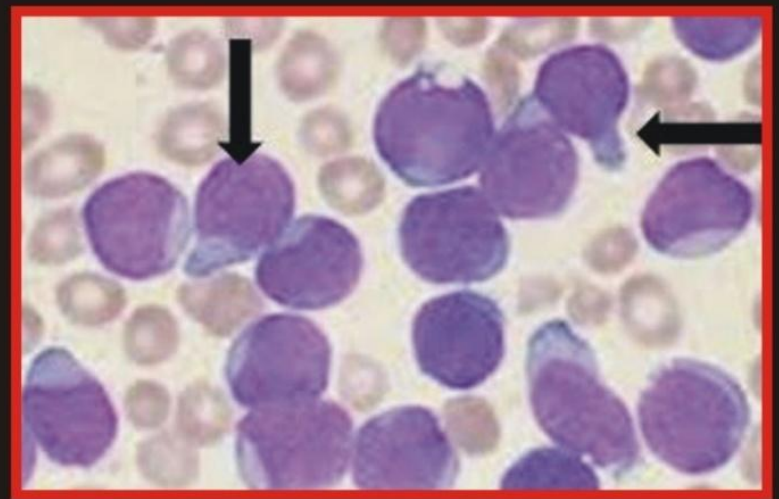

Fig. 8D: Hand mirror appearance in the blasts of ALL (Leishman's stain X1000) 


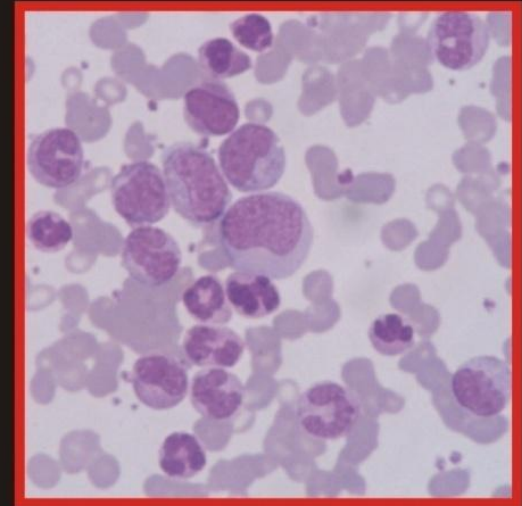

Fig. 9A: CML-CP, PS showing immature myeloid cells, mature neutrophils and basophils (Leishman's stain, $\mathrm{X} 400$ )

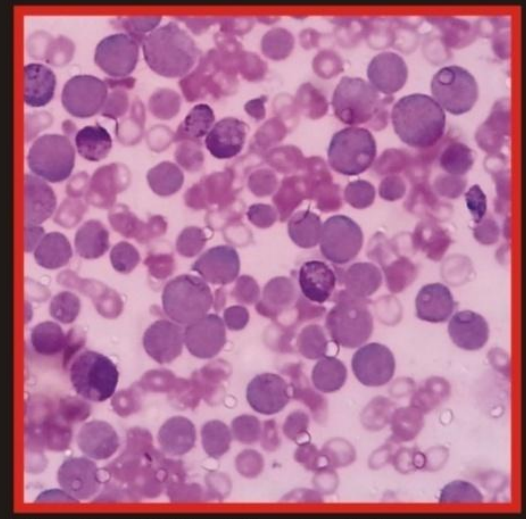

Fig. 9B: CML- Blast crisis phase, PS showing blasts and basophils ( Leishman's stain, $X$ 400).

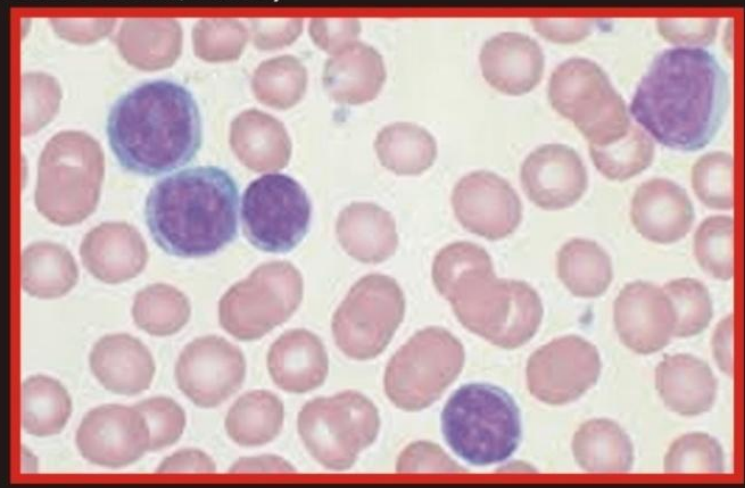

Fig. 10A: CLL, PS showing mature lymphocytes (Leishman's stain, X1000)

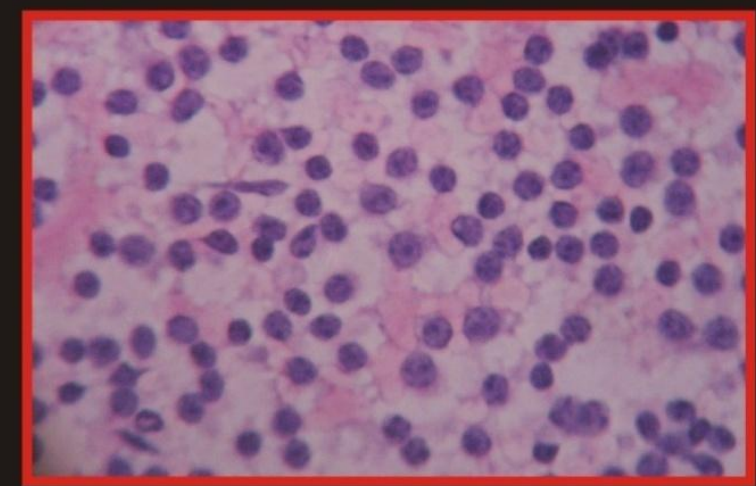

Fig. 10B: PS - Prolymphocytic transformation of CLL (Leishman's stain, X400) 